\title{
Advertising in Cambodia
}

Cambodia is currently in the process of adopting a free-market system, and one of the first consumer goods that local importers have introduced on a large scale is cigarettes. The government has begun to try to control this burgeoning market through legislation and increased taxes on foreign cigarettes. The Minister of Health's request on 17 July 1995, to the Bureau of the Council Ministers, for a ban on cigarette advertising on radio and television is an example. Although the initial request was rejected, a compromise was reached where health warnings would appear on television and radio cigarette advertisements. Notwithstanding these attempts, tobacco advertising flourishes with little or no restrictions in Cambodia.

To better understand the advertising strategies being employed by the tobacco industry, the Adventist Development and Relief Agency (ADRA)/Cambodia organised its Master of Public Health students - all belonging to the Ministry of Health - to conduct a street survey of advertising signs on the exterior of buildings in the capital, Phnom Penh, in October 1994. For the survey, 12 teams were formed of one or two people. Twelve main streets throughout the city were selected. The teams then walked along a section of their designated streets tallying all the advertising signs they saw. Of the 8495 signs recorded, $4123(48.5 \%$ of all signs) advertised tobacco products; 2598 (30.6\%) advertised alcohol; $766(9 \%)$ advertised non-alcoholic (soft) drinks; 521 (6.1\%) were for various consumer products; and 487 $(5.7 \%)$ advertised the name of the business operating in the building.

About six months later, the government imposed a tax on such advertising and many

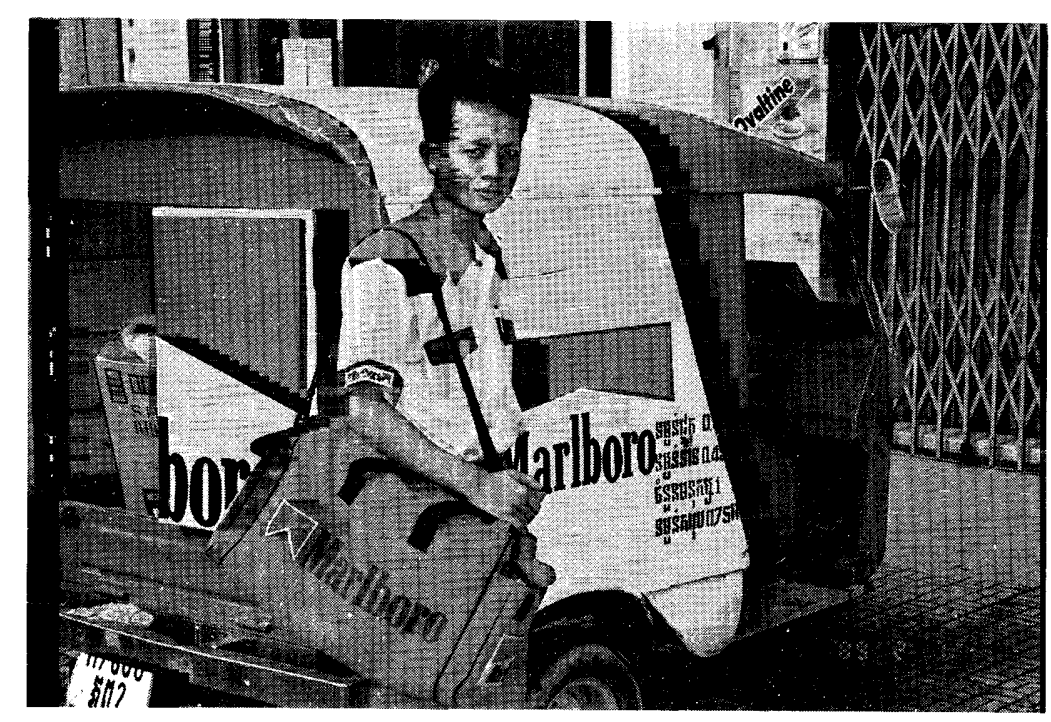

Figure 1 Marboro delivery man alongside his tri-wheeled vehicle. signs were pulled down. Signs on buildings, $\stackrel{\overrightarrow{\vec{F}}}{\stackrel{\overrightarrow{0}}{\circ}}$ though, are only one aspect of tobacco ad- $\frac{C}{\sigma}$ vertising. In Cambodia, tobacco companies $\frac{\overline{\bar{N}}}{\overline{\frac{1}{a}}}$ have become very creative in the ways they $\vec{\Phi}$ have devised to market brand names. One widely used form of advertising is large ${ }^{\infty}$ umbrellas. They have become ubiquitous be- $\vec{\circ}$ cause, not only are they given out to tobacco $\vec{\overrightarrow{ }}$ vendors who operate from good locations, but $\stackrel{\omega}{\omega}$ vendors who do not sell cigarettes buy them as $\vec{?}$ they are sought-after items - especially when ${ }_{-}$ advertising the popular, typically foreign $\dot{\sigma}$ brands. A woman who has a small grocery shop selling tobacco on a busy street, told us how the cigarette companies gave her free $\vec{z}$ umbrellas. They even come by every few days to wash the umbrellas and replace them if they $\stackrel{S}{\mathcal{S}}$ are broken or damaged. She also mentioned $\vec{\theta}$ that instead of buying the cigarettes for her $\stackrel{\odot}{\circ}$ shop from wholesalers in tri-wheeled vehicles, as seen in figure 1 , she buys directly from the market because it is cheaper.

The most interesting arrangement involving umbrellas is between the tobacco companies $\stackrel{2}{\mathbb{Q}}$ and the Market Committee, the government agency that overseas the central and other $\frac{0}{3}$ market areas. The Marlboro and Alain Delon $\supset$ umbrellas one sees around the crowded stalls are mandatory - "rented" by stall keepers who $\overrightarrow{0}$ pay 400 riel (16 cents) per day.

As is common in Western nations, the local ถึ industry, trading on sex appeal, uses beautiful young women to distribute free cigarette samples in Cambodia. The negative connota- $\overrightarrow{\overrightarrow{0}}$ tions of such a job are overcome by a monthly salary of \$US80-90, which is five to six times the average government salary. Figure 2 shows

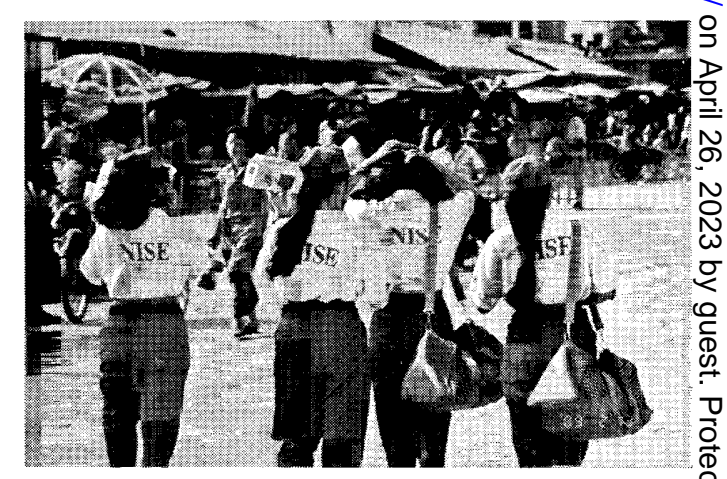

Figure 2 Young girls handing out British-made NISE cigarettes in a marketplace.

NISE girls, around 19 years old, strolling $\frac{8}{0}$ through a market area handing out pretty smiles and free cigarettes to the all-too-willing motor taxi drivers and others.

Marlboro Man advertisements are common on cyclos (tricycle taxis) (figure 3) and are considered highly prestigious by their owners, 


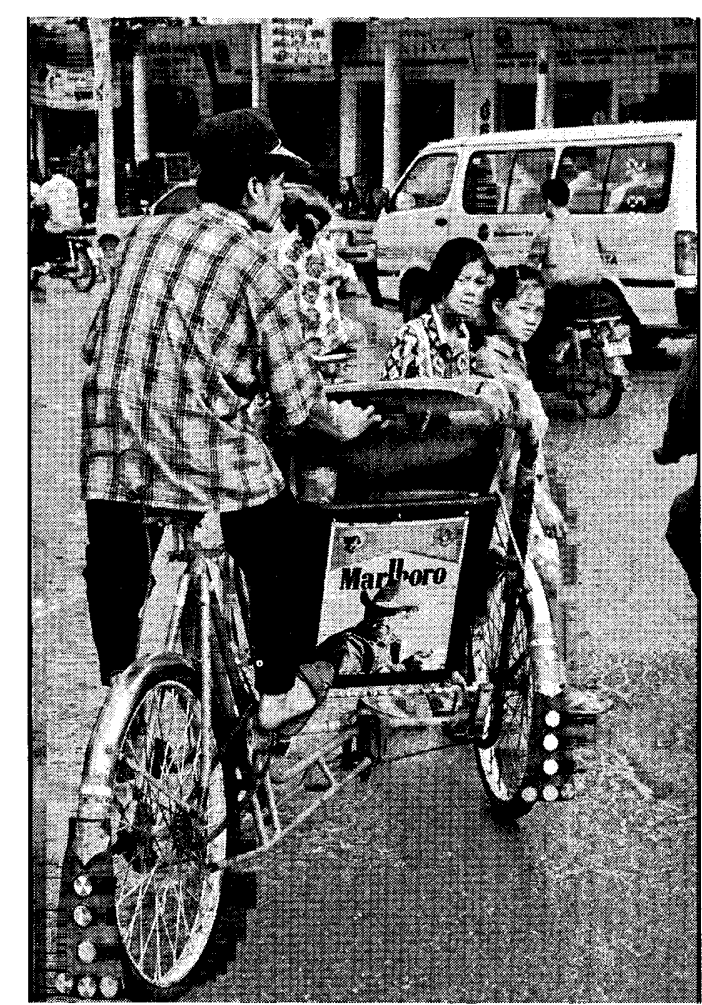

Figure 3 Marlboro advertisements are common on cyclos (tricycle taxis).

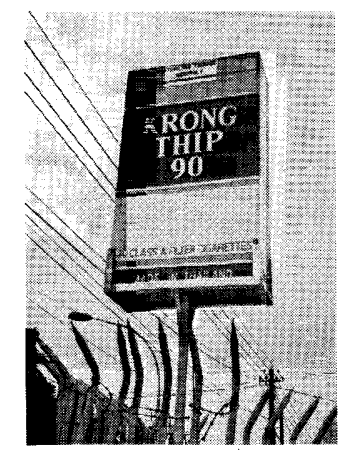

Figure 4 A giant elevated box of Krong Thip 90 cigarettes, made by the Thailand Tobacco Monopoly.

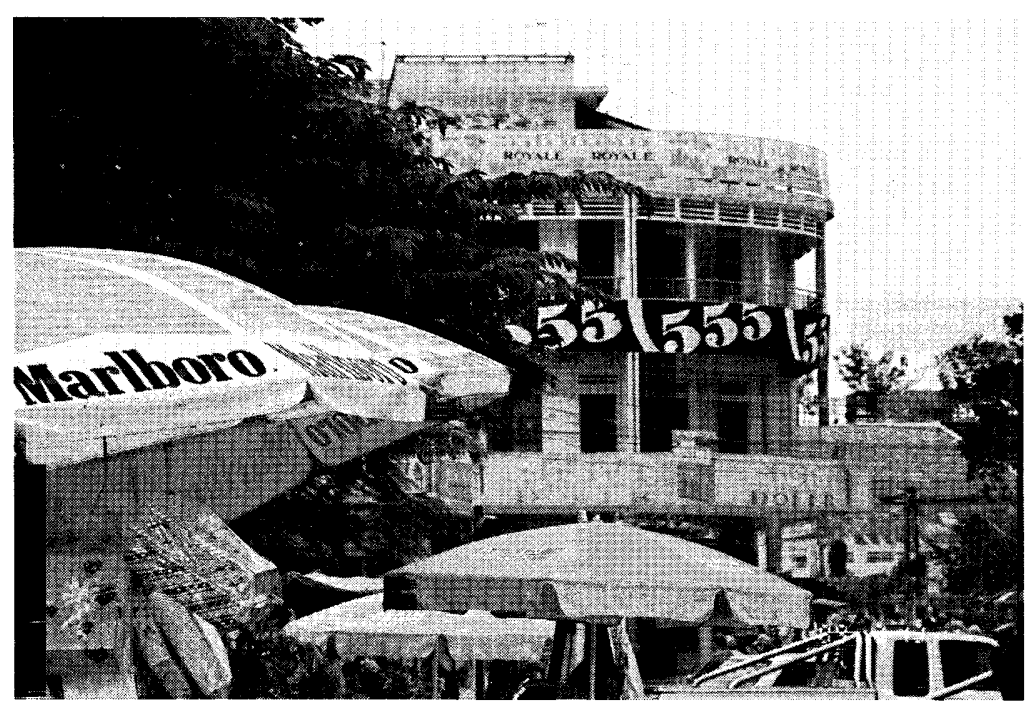

Figure 6 Cigarette advertising on all three levels of a building in Phnom Penh. The owner of this building earned $\$ U S 600$ per year for the first-floor row of Doler ads. who often pay for them. Restaurant walls generally feature several cigarette advertisements, which the cigarette companies themselves put up. Restaurant owners are pleased to have their otherwise bare walls decorated with popular pictures. No money is exchanged. Giant elevated tobacco boxes are another form of advertising, commonly favoured by Krong Thip 90, a brand produced by the ज़ Tobacco Monopoly (figure 4).

Snooker and video game amusement clubs targeting young people are plaste advertisements inside and out. One sish venue has a large Mild Seven sign outsidge, placed there free on condition that large Mild Seven advertisements were placed inside the club as well. The doorman was proudly wearidig a free Mild Seven shirt.

Another widespread form of advertitising is the kiosk (figure 5). Kiosks along the main roads can get up to $\$$ US50 a year foröigarette advertising. Considering the fact that such advertising spruces up their stands, they view an extra $\$ U S 50$ as a windfall.

Around the Central Market area of Phnom Penh, it is apparent that there is $\frac{\pi}{a}$ higher concentration of advertisements becagse of the large number of people exposed to.hem. A high price can be secured for these sfgns. One building owner we spoke with gets $\$$ US600 per year for the first-floor row of Doler advertising (figure 6).

Figure 7 shows Japan Tobacco's \&pproach to the "ice cream wagon" traditional used to sell ice cream to children. The Khme writing says, "The taste is No. 1 all over the world." For vendors who have prime locations, the tobacco companies provide these fadcy carts and signs free of charge but, for idess ideal locations, the tobacco companies mayofffer just a sign or poster, and the retailer onsupplies his/her own display case. Such stands range from the elaborate (figure 7), which offer a complete range of brands, to the simple wooden shelf holding only a few packs of one or two brands and quite often lookeक्षfarter by children. One girl interviewed was 14 gears old (figure 8 ) but many are younger. These smaller tobacco stands are often convenient located along roads, and also serve as gasolinie stands for motor taxis and others. Within a wusy city block, several of these combination nobacco/ gas dealers may be located.

N

Currently, Cambodia boasts moreothan 60 brands of tobacco, ranging in price from the prestigious 555 produced by British Tobacco and selling for 2200 riel (88 eents) per packet to the locally made Liberation priced at 350 riel (14 cents) per packet. Hogndmade cigarettes can be purchased for as litfle as 100 riel (4 cents) per 20 cigarettes (no pa@kaging). Prices are fairly standard at the variou outlets.

One woman (figure 9) who hads a large street-side stand along a main rad, said proudly that she was provided with case, an umbrella, and a poster. Her total sales are about $40000-50000$ riel (\$US16-20) per day, with about $10 \%$ of that as profit.

In general, Cambodians view a tobacco advertisement as glamorous. A Mild Seven 


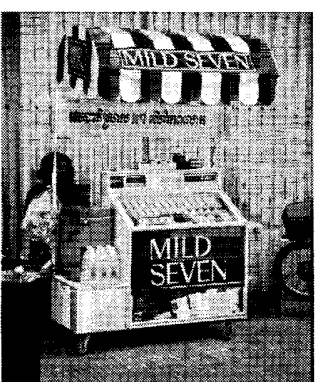

Figure 7 fapan

Tobacco's approach to the "ice cream wagon".

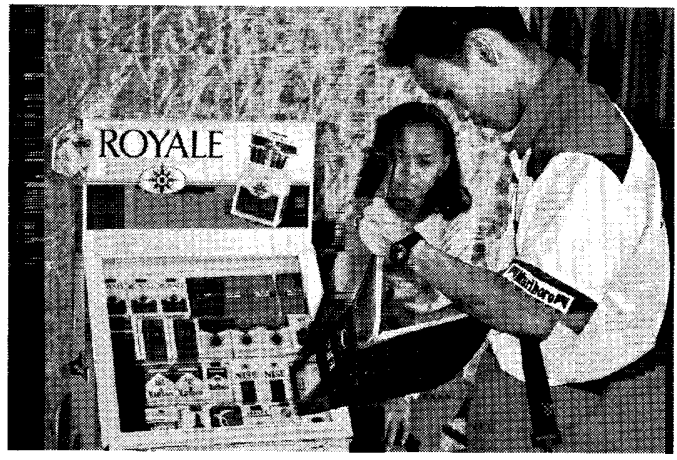

Figure 8 A 14-year-old girl looking after a small tobacco stand.

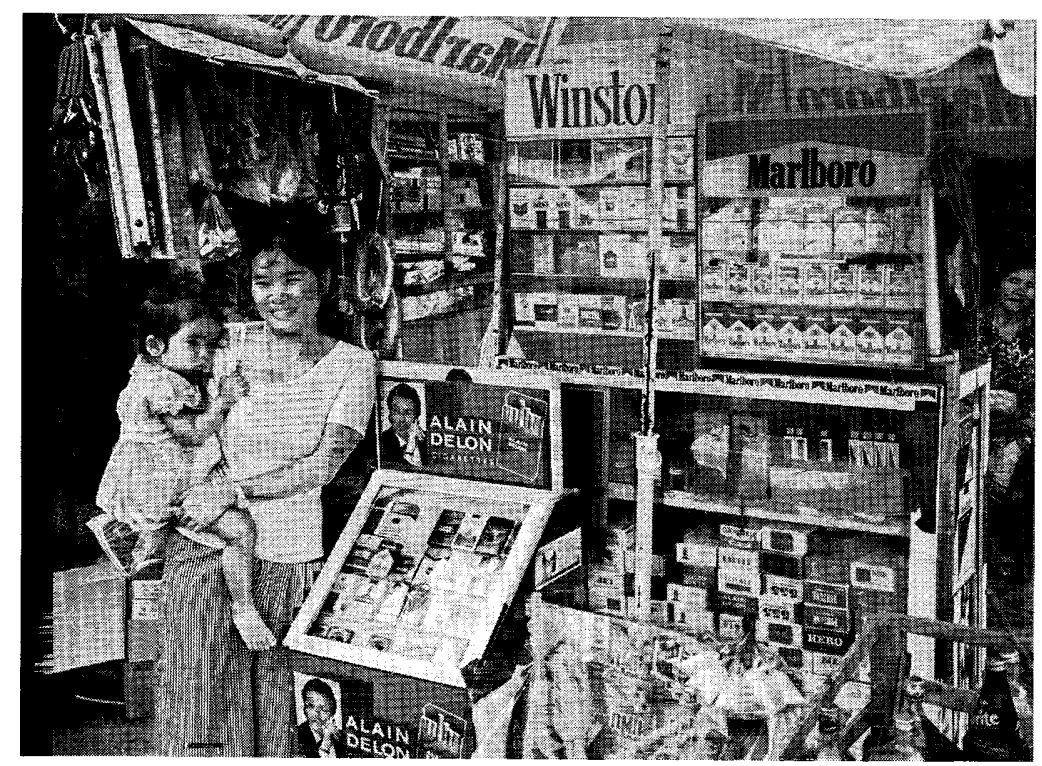

Figure $9 A$ woman by her large, street-side, cigarette stand, which brings her \$US16-20 per day in sales, $10 \%$ of which is profit.

shirt is considered fashionable; a 555 sports car poster as a coveted wall cover; and the Marlboro Man, wielding his cigarette, as the ultimate macho image. In Cambodia, the expected protocol when receiving guests is to offer them a cigarette. At a wedding or party, it is shameful if foreign cigarettes are not passed out to all. The cigarette has effectively come to symbolise sophistication, power, and prestige.

We have conducted 30-cluster surveys in Phnom Penh and Siem Reap Province (north- 응 ern Cambodia), involving 360 randomly selected males aged 15-45 years in Phnom Penh and $O$

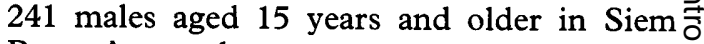
Reap. Across these age groups, average smoking rates were $64.7 \%$ and $86.3 \%$, respectively. $\stackrel{\vec{\sim}}{\vec{S}}$ Given the very high smoking rates in ruralo areas, one would suspect that there is a long- 흠 standing custom of smoking, maintained and $\frac{\bar{\sigma}}{\bar{\sigma}}$ made more prestigious by advertising.

Do these various marketing strategies pay off? Advertising has permitted foreign brands $\overrightarrow{0}$ that are sold at much higher prices to dominate the market. In our surveys we asked respon- $\vec{\omega}$ dents what brand of cigarettes they usually smoked. In Phnom Penh, where the adver- of tising for foreign tobacco is mainly concen- $\rightarrow$ trated, four of the following top five brands nominated by our respondents were foreign.

(1) FINE (France)

(2) 555 (UK)

(3) Marlboro (US)

(4) NISE (UK)

(5) Fortune (local).

The total average price is 1564 riel ( 62 cents) per packet. By contrast, four of the five top brands in the rural area of Siem Reap were local-the most popular being handmade cigarettes selling for about 100 riel (4 cents) ڤ per 20 cigarettes. NISE was reportedly popular $\stackrel{\unrhd}{\varrho}$ in both surveys due, we believe, to the $\overrightarrow{\overrightarrow{0}}$ nationwide lottery run by its distributors, $\frac{0}{3}$ where a lucky purchaser has the chance to win a new car - beyond the wildest dreams of most of the population. The lottery form of mar- $\frac{\overrightarrow{0}}{0}$ keting has proved so popular that others, including beer companies, are jumping on the bandwagon.

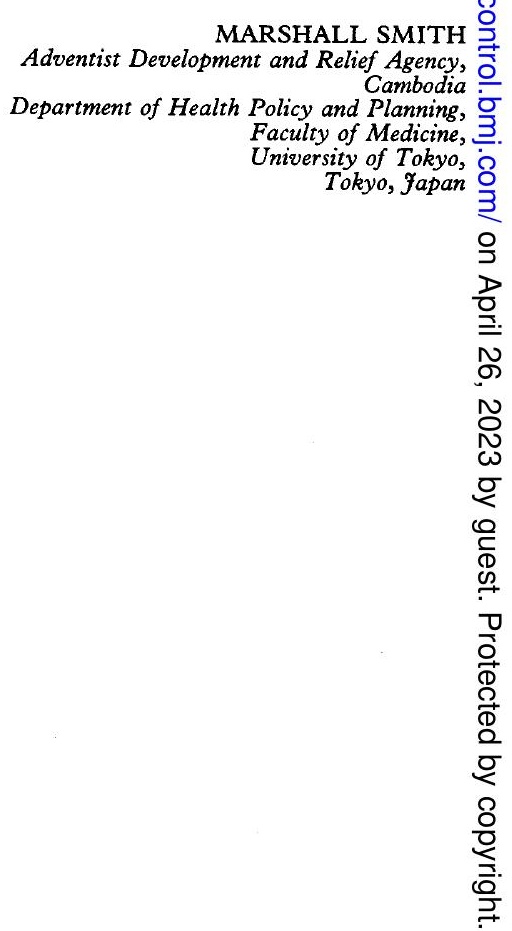

